\title{
INTRANET DO GRUPO COPREL: USOS E AVALIAÇÕES
}

\section{INTRANET OF THE COPREL GROUP: USES AND REVIEWS}

\author{
Marcela Prass Scheffle \\ Pós-Graduanda em Assessoria de Comunicação e Marketing pela Universidade de Cruz Alta (UNICRUZ) \\ Pesquisadora do CIPECOM - Centro Integrado de Pesquisa em Comunicação (CPIPECON) \\ Graduada em Comunicação Social pela Universidade de Cruz Alta (UNICRUZ) \\ E-mail: marcela.scheffler@gmail.com
}

\section{Fabiana Iser}

Mestre em Ciências da Comunicação pela Universidade do Vale dos Sinos (UNISINOS) Professora da Universidade de Cruz Alta (UNICRUZ)

E-mail: fiser@unicruz.edu.br

\section{RESUMO}

O presente trabalho é resultado de uma pesquisa empírica realizada em um grupo de empresas que recentemente implantou uma ferramenta online de comunicação interna, chamada Intranet. O objetivo foi realizar uma análise da comunicação organizacional a partir de entrevistas com os colaboradores, para avaliar a utilização da ferramenta, bem como das demais ações/meios de comunicação interna. Contatou-se a existência de problemas de comunicação interna, bem como, os aspectos de dificuldade na implantação efetiva da ferramenta Intranet. Também foi possível avaliar quais ações de comunicação tem trazido resultados positivos à organização, fornecendo subsídios para o planejamento de estratégias de comunicação interna que auxiliem na integração dos colaboradores entre si e com a empresa, o que é fundamental para o sucesso de uma organização.

Palavras-chave: Intranet. Comunicação. Organizacional. Público Interno. Tecnologia.

\begin{abstract}
This paper is the result of an empirical survey of a group of companies that have recently implemented an online tool for internal communication, called Intranet. The goal was to conduct an analysis of organizational communication from interviews with employees, to evaluate the use of the tool, as well as other actions / internal media, contacted the existence of internal communication problems, as well as aspects of difficulty in the effective implementation of Intranet tool. It was also possible to evaluate which communication actions
\end{abstract}


have brought positive results for the organization, providing support for the planning of internal communication strategies to assist in the integration of employees with each other and with the company, which is critical to the success of an organization.

Keywords: Intranet. Organizational communication. Workforce. Technology.

\section{INTRODUÇÃO}

O mundo está cada vez mais digital. E para nos adequarmos a essa realidade, adaptamos nossa rotina pessoal e profissional, transformamos nosso consumo, digitalizamos nossos relacionamentos. E as empresas buscam estar adaptadas a essa realidade, se reinventando em suas plataformas digitais já utilizadas e criando novas formas de se comunicar com seus públicos. Mas esta conexão das empresas/instituições no universo digital vai muito além de propiciar mais um canal de comunicação e/ou atendimento. A implantação de uma nova ferramenta de comunicação, seja ela online ou em mídia tradicional, demanda planejamento, gera novas demandas de trabalho, pode causar estranhamento e exige adaptação. E as mídias digitais geralmente buscam a interação de seus públicos, para se constituírem como um meio de comunicação oficial e se reconstruírem a partir das demandas de seus usuários.

Neste contexto, nos propomos a estudar uma ferramenta de comunicação específica para o público interno do grupo Coprel, sediado em Ibirubá-RS, chamada Intranet ${ }^{l}$. Chegamos a este objeto de estudo a partir da necessidade latente no grupo de avaliar a implantação da ferramenta, o que até então ainda não havia sido feito, bem como, coletar impressões dos próprios colaboradores visando elaborar melhorias ou adaptações na ferramenta, caso necessário. No grupo de empresas pesquisado, a Intranet se constitui com uma estrutura semelhante a um website, porém o seu acesso é estritamente restrito aos colaboradores, sendo necessária uma senha pessoal que é fornecida pela empresa.

Com a presente pesquisa, pretendemos contribuir com os estudos de comunicação interna organizacional e Intranets corporativas. Também pretendemos fornecer ao grupo estudado informações importantes sobre os usos que os seus colaboradores fazem em relação à Intranet, apontando sugestões para uma melhor utilização da ferramenta e que poderão ser aplicadas internamente. Por fim, buscamos também valorizar a importância da comunicação interna nas instituições, além das possibilidades e limitações das ferramentas de comunicação online para otimizar os processos de trabalho e interação nas organizações. 


\section{COMUNICAÇÃO ORGANIZACIONAL}

Nenhuma instituição sobrevive sem comunicar-se com seus públicos. As empresas precisam ser reconhecidas por seus colaboradores ${ }^{2}$, clientes, fornecedores, comunidade e imprensa. Um dos papeis da comunicação é estabelecer relações com estes diferentes públicos que possuem necessidades distintas e requerem estratégias diversas. A definição proposta pela professora Elisabeth Saad Corrêa dá conta de que a comunicação organizacional:

Tem por função estabelecer os canais de comunicação e respectivas ferramentas para que a empresa fale da melhor maneira com seus diferentes públicos. Neste sentido, todas as possibilidades de relacionamento com esses públicos devem estar integradas e alinhadas pela mesma visão estratégica, por um discurso uniforme e pela coerência das mensagens (CORRÊA, 2005, p. 101).

O trabalho do comunicador social nas instituições se relaciona com o planejamento estratégico, e precisa considerar que cada diferente público exige novas estratégias e ferramentas para construir relações de confiança com a empresa.

O presente trabalho centra-se na comunicação interna, que diz respeito a seus colaboradores. A comunicação interna é uma ferramenta fundamental para as organizações, possibilitando aos funcionários o conhecimento sobre a empresa em que trabalham, informando sobre os processos internos, sobre o dia-a-dia da instituição, e proporcionando, inclusive, um clima favorável ao trabalho, à interação e ao bom relacionamento entre os empregados e destes com a equipe diretiva.

Utilizamos a definição de Margarida Kunsch (apud SCROFERNEKER, In: DORNELLES, 2007, p. 83) para a comunicação interna, a qual, segundo a autora, "se constitui em um setor planejado com objetivos bem definidos, para viabilizar toda a interação possível entre a organização e seus empregados [...].” No trabalho de Scroferneker (2007), ao trazer diversos entendimentos dos estudiosos da área, destacamos a posição de Argenti (apud SCROFERNEKER, in: DORNELLES, 2007, p.84), que reforça a definição anterior ao contextualizar o conceito: "A comunicação interna do século XXI envolve mais do que memorandos, publicações e suas respectivas transmissões; envolve desenvolver uma cultura corporativa e ter o potencial de motivar a mudança organizacional." Reside aí o grande desafio dos profissionais de comunicação, afinal, este é o papel, definido pelos autores como missão básica da comunicação interna: "Contribuir para o desenvolvimento e a manutenção de um clima positivo, propício ao cumprimento das metas estratégicas da organização e ao crescimento continuado de suas atividades e serviços à expansão de suas linhas de produtos." (TORQUATO, apud SCROFERNEKER, in: DORNELLES, 2007, p.83). 
Ainda que de fundamental importância nas organizações, a comunicação interna enfrenta muitas dificuldades. Quando executada pelos mesmos profissionais que também desempenham as funções de assessores de imprensa, a comunicação interna pode ficar em segundo plano, sendo priorizado o atendimento à imprensa e edição de conteúdos para os canais de comunicação voltados ao público externo. Mas o que os estudiosos defendem é que a comunicação eficaz se faz dando a importância necessária às informações para os colaboradores:

\begin{abstract}
O cliente externo está cada vez mais exigente, então, é preciso estar preparado para atendê-lo da melhor maneira possível, e a profissionalização é a melhor maneira de atingir os resultados necessários às empresas. Portanto, treinamento e valorização do cliente interno ${ }^{3}$ começam a possuir seu peso e a exigir maiores investimentos. (CINEGAGLIA, In: FRANÇA, 2014, p. 123)
\end{abstract}

A autora também considera que o conhecimento do colaborador sobre a empresa está além da funcionalidade laboral, mas influencia até na autoestima em relação ao trabalho.

\footnotetext{
Em relação ao colaborador, seu comprometimento com o negócio está relacionado ao nível de conhecimento que possui sobre a empresa, e implicará diretamente o sucesso ou fracasso da organização, logo percebe-se como são fundamentais a transparência e a prioridade das informações a esses clientes. (CINEGAGLIA, In: FRANÇA, 2014, p. 123)
}

Desta forma, justifica-se os esforços e investimentos na comunicação interna, bem como os estudos na área para aprimorar as formas de comunicação e as ferramentas onde serão divulgadas essas informações.

\title{
3 O GRUPO COPREL
}

A Coprel - instituição onde se dará a pesquisa - envolve um grupo de cooperativas e empresas parceiras, que atuam conjuntamente e compartilham dos mesmos métodos de gerenciamento, utilizando de forma conjunta ferramentas e informações relacionadas à comunicação interna, onde inclui-se a Intranet.

A Coprel Cooperativa de Energia, cujo negócio é a distribuição de energia elétrica, é uma cooperativa com sede em Ibirubá/RS, e atuação em 72 municípios do Estado do Rio Grande do Sul. Dentre as empresas do grupo, concentra o maior número de funcionários e a maior parte das funções administrativas. A maioria dos colaboradores utiliza a internet diariamente em seu trabalho, porém em alguns setores o uso de computador não é necessário, e em outros setores, não é possível devido ao fato de o trabalho ser desenvolvido a campo. 
A Coprel Cooperativa de Geração de Energia e Desenvolvimento, com sede também em Ibirubá/RS, é uma cooperativa oriunda da Coprel Energia. Possui constituição jurídica independente, mas compartilha certa unidade administrativa com sua cooperativa de origem. $\mathrm{O}$ principal negócio da Coprel Geração de Energia e Desenvolvimento é administrar e operar usinas de geração de energia elétrica, (próprias e em parceria com outros investidores). A Coprel Geração possui uma fábrica de postes e artefatos de concreto - cujo grupo de funcionários não possui acesso à internet no trabalho; e é controladora/majoritária de outras duas empresas: a Amisa e a Triway. Ainda com relação ao grupo de funcionários da Coprel Geração, da mesma forma que a Coprel Cooperativa de Energia, os colaboradores que trabalham nas questões administrativas possuem acesso à internet, no entanto os que trabalham a campo, não dispõem do acesso à internet para uso diário no trabalho.

A Amisa - Auto Mecânica Ibirubá S.A., coligada à Coprel Geração e Desenvolvimento, é uma empresa do ramo automotivo, atuando na venda de produtos e serviços com atuação em 22 municípios do Estado, tendo como sede a cidade de Ibirubá/RS, filial em Panambi/RS, (nesta última com extensão para Palmeira das Missões/RS), e ainda atua na comercialização de combustíveis, nas cidades de Ibirubá e Quinze de Novembro/RS. O uso da internet no trabalho é visivelmente divido entre os setores administrativos - que a necessitam como ferramenta de trabalho; e os setores operacionais, que não utilizam computadores para as tarefas do trabalho.

Encerramos a apresentação das empresas do grupo estudado falando sobre a Triway, outra empresa controlada pela Coprel Geração. A Triway é uma operadora de telecomunicações com sede em Ibirubá e atuação se estendendo para mais municípios da região, (atualmente são 18 municípios). Seu ramo de atividades é a comercialização de serviços de internet e telefonia. Por trabalhar com tecnologia, todo o grupo de funcionários conhece o funcionamento da internet, porém os colaboradores que trabalham a campo não precisam conectar-se à Intranet para realizar seu trabalho, diferentemente dos empregados que ocupam as funções de vendas e administrativas.

Apesar da variedade e distinção entre as empresas do grupo, de modo geral será utilizada a expressão "Coprel" ou "Grupo Coprel" ao se referir ao conjunto de instituições pesquisadas, exceto ao se tratar de alguma empresa ou cooperativa em específico. Cabe ressaltar ainda que todos os colaboradores, apesar de estarem vinculados a quatro diferentes empregadores, possuem uma unidade ideológica, administrativa e funcional, além de técnica. Nenhuma empresa do grupo pode ser tomada separadamente na comunicação interna - assim como a Intranet, que é utilizada de forma semelhante em todas as empresas. 
Outro aspecto importante a se destacar no grupo estudado é sua estrutura organizacional: as empresas do grupo estão organizadas em um modelo de gestão horizontal, assim, as rotinas de trabalho são independentes, ao mesmo tempo em que atuam de forma conjunta para o mesmo fim. Buscamos na conceituação de Motta (1995), o modelo estrutural e conceitual que se assemelha ao conceito adotado no grupo.

[...] a corporação horizontal, é um novo modelo organizacional, organizado por processos e não por tarefas. Cada processo possui um proprietário e objetivos de desempenho específicos. A hierarquia é, por definição, achatada, com grande uso de equipes de trabalho autossustentadas e gerenciadas. A organização é voltada para o cliente; a satisfação deste é a medida primária do desempenho da empresa. Os lucros virão como consequência da satisfação dos clientes. (MOTTA, 1995, p. 16).

Trabalha-se, internamente, o conceito de "Força do Grupo", ou seja, a importância de todos estarem informados sobre, inseridos em, e comprometidos com todas as empresas, independente de qual for o setor de trabalho. Desta forma, não há uma separação clara por departamentos, mas sim por diferentes processos. Aí reside o grande desafio da comunicação interna, na qual a Intranet tem importante papel: consolidar a cultura de integração, participação e comprometimento com todas as empresas do grupo, com o objetivo maior de trazer resultados a partir da satisfação dos clientes e dos cooperantes ${ }^{4}$.

\subsection{INTRANET: O PRODUTO E A PRODUÇÃO}

O avanço das tecnologias e a utilização da internet em grande parte das atividades realizadas dentro de uma empresa atualmente requerem constantes atualizações - por parte das empresas e dos funcionários, para dar conta dos novos suportes tecnológicos disponíveis no mercado e necessários para o trabalho em qualquer setor. Contudo, é preciso estar atento para não investir em uma tecnologia simplesmente por que ela existe, mas sim pensando nos reais benefícios de sua utilização. Neste sentido, Martin (apud CORRÊA, 2005), salienta que:

\footnotetext{
Internet não deve ser considerada apenas mais um meio de comunicação. Ela é o sistema de circulação da nova economia [...] a armadilha que geralmente vemos é confundir a tecnologia e o que ela possibilita com as necessidades do mercado. A internet é um meio para um fim e não um fim em si mesma. Reconhecer essa diferença é igual à compreensão da sociedade sobre o telefone, que se tornou uma aplicação fundamental para facilitar a comunicação e não porque era apenas uma inovação tecnológica (MARTIN, apud CORRÊA, 2005, p. 106).
}

Desta forma, entende-se que a implantação de uma ferramenta como a Intranet deve ser motivada pelos reais benefícios que pode proporcionar à comunicação interna. Determinada empresa que fornece este serviço a define da seguinte forma: 
Conceito derivado da internet, a Intranet é uma rede privada acessível somente para o corpo funcional. Nela, é possível armazenar arquivos e divulgar mensagens para a equipe. Permite um pouco mais de interatividade entre os membros, dependendo da ferramenta selecionada. Exige infraestrutura tecnológica dentro da empresa para suportá-la. Se não for bem administrada, pode tornar-se apenas um depósito de informações, sem propósito de comunicação ${ }^{5}$.

É necessário destacar que a Intranet não representa um site de "rede social" entre os colaboradores. Pois, para um site da web ser considerado um "site de rede social", são necessárias algumas características, ou seja, permitir através de seus recursos: "a construção de uma persona através de um perfil ou página pessoal; a interação através de comentários; e a exposição pública da rede social de cada autor" (BOYD \& ELLISON, apud RECUERO, 2009, p. 102). Nenhuma destas características está prevista na Intranet, pois até mesmo a criação do perfil pessoal está condicionada às normas da empresa. Também não está disponível a interação via comentários, a não ser em espaços delimitados especialmente para isso. E a rede de usuários dentro da ferramenta é única, não permitindo subdivisões em diferentes redes de contatos.

Compreendemos que a Intranet, sistema adotado com o objetivo de ser mais uma ferramenta a favor da comunicação interna na organização pesquisada, necessita de estratégias para que seu uso seja efetivo, e haja retorno sobre o investimento feito. Neste estudo sobre o comportamento dos funcionários na Intranet, pretendemos contribuir para a melhoria das estratégias de comunicação interna e para mensurar se os esforços feitos até então têm dado resultado.

A Intranet na Coprel foi implementada em dezembro de 2012. Para acessar a ferramenta, é necessário possuir acesso à internet (o que não precisa ser necessariamente dentro da empresa, mas em qualquer local conectado à web). No entanto, somente com um login e senha $^{6}$, fornecido pela empresa, é possível acessar os conteúdos da página.

O cadastro dos colaboradores na ferramenta ocorre de modo manual, bem como as instruções para uso. A disponibilização de conteúdos na Intranet obedece a filtros préestabelecidos, definindo quem pode ter acesso a cada conteúdo/informação. Atualmente, grande parte dos conteúdos é disponível a todos os colaboradores, como exemplo: notícias, aniversariantes, comunicados, dicas, etc.

Navegando na ferramenta, é possível conhecer as empresas, setores e colaboradores que fazem parte de cada setor. Documentos de uso comum e comunicados institucionais ficam disponíveis na Intranet. Os conteúdos são integralmente produzidos no setor de comunicação da Coprel, contemplando todas as cooperativas/empresas do grupo. 
Os objetivos da Intranet, buscados desde sua implantação, são: centralizar as informações em uma plataforma única de comunicação, propiciar mais agilidade na disseminação de informações, incentivar a comunicação entre os colaboradores, proporcionar em um canal único as informações necessárias para o entendimento e conhecimento do grupo.

E dentre os desafios desta pesquisa, estão identificar o possível engajamento dos colaboradores na ferramenta, bem como as necessidades dos funcionários quanto à comunicação interna, avaliando o quanto a ferramenta é capaz de atender a essas necessidades, propondo sugestões de melhoria e aprimoramento da ferramenta, tanto em questões técnicas como de conteúdo.

A seguir, apresentamos a título de visualização a página inicial da Intranet, para um usuário padrão (não administrador) onde se pode perceber como as informações estão dispostas na página. É possível observar uma barra de rolagem extensa no canto direito da imagem, revelando que a página inicial se estende mais. Também se constata a existência de diversos menus.

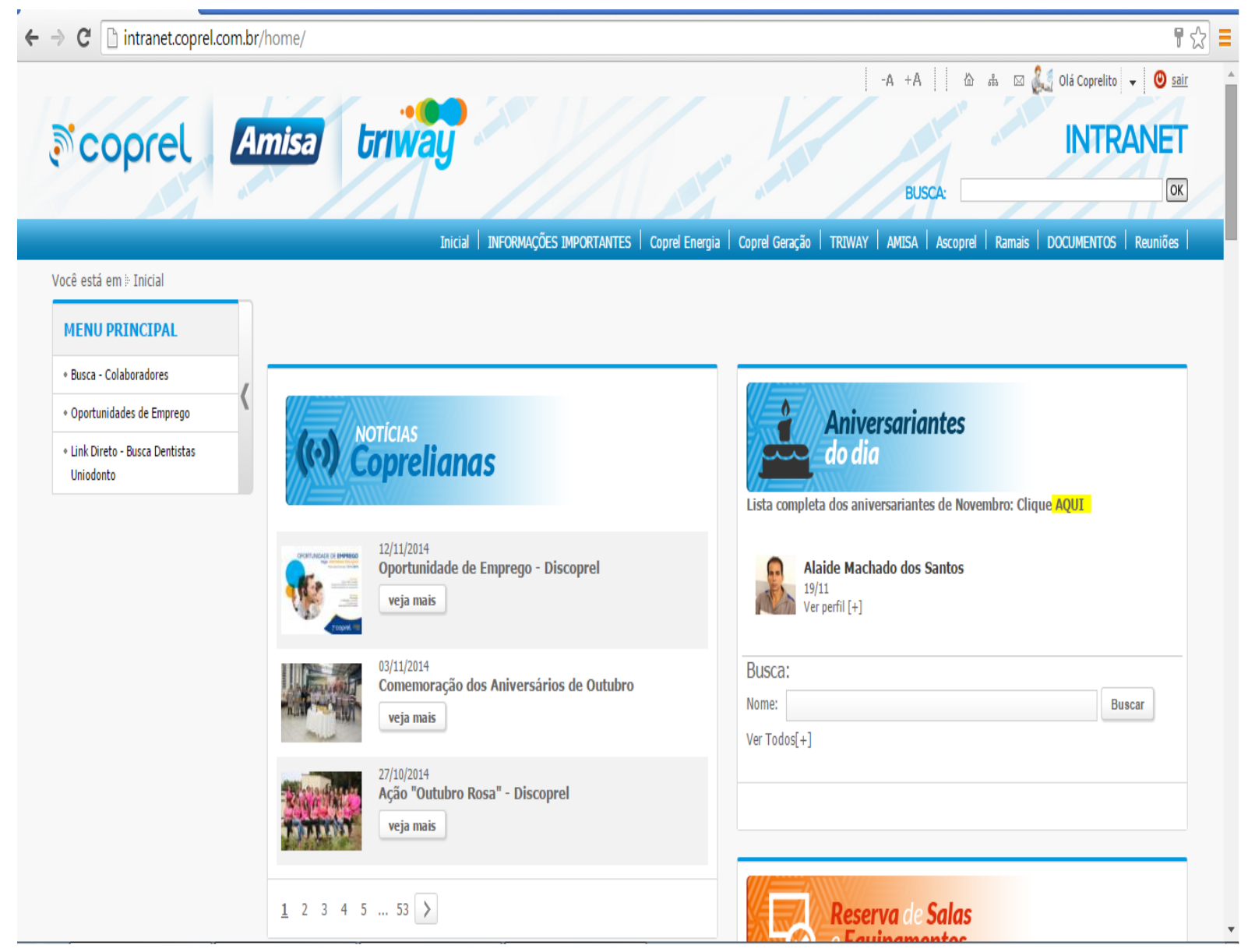

Figura 1: Página inicial da Intranet Coprel 


\title{
4 METODOLOGIA
}

Para atender aos objetivos deste estudo, além da pesquisa bibliográfica, entendeu-se ser necessária uma análise da ferramenta Intranet, bem como do público usuário deste sistema de comunicação interna, através de pesquisas. Realizada esta etapa, fizemos um levantamento dos dados de acesso da Intranet, através da ferramenta Google Analytics ${ }^{7}$.

A pesquisa aos colaboradores se deu através de questionário semi-aberto, com questões estruturadas, obedecendo ao mesmo padrão para todos os colaboradores, visando atender ao método de "pesquisa institucional ou auditoria da comunicação organizacional" (KUNSCH, In: DUARTE, BARROS, 2010), conforme definição da autora:

\begin{abstract}
A auditoria da comunicação organizacional tem como propósito fundamental pesquisar, examinar e avaliar como funciona o sistema de comunicação do ponto de vista da eficácia e eficiência, no âmbito corporativo como um todo ou em partes, compreendendo a comunicação administrativa, a comunicação interna, a comunicação institucional e a comunicação mercadológica. Tudo dependerá das necessidades, dos objetivos e da conjuntura das organizações. Visa também corrigir desvios, prevenir e encaminhar soluções de problemas, aperfeiçoar o sistema de comunicação de uma organização, buscando com isso melhorar seu desempenho. (KUNSCH, In: DUARTE, BARROS, 2010, p.238).
\end{abstract}

Consideramos para esta pesquisa o universo de 368 colaboradores em 30 de junho de 2014, sendo: 10,5\% da Coprel Geração, 4,5\% do Triway, 31\% da Amisa e 54\% da Coprel Energia. Elaboramos questionários para todos os colaboradores, e, conforme a autora, "os questionários e as entrevistas são considerados os melhores e mais completos dos instrumentos, pois permitem obter o máximo de informações" (KUNSCH, In: DUARTE, BARROS, 2010, p. 242).

Primeiramente, este questionário foi disponibilizado na própria Intranet, como forma de medir inicialmente, o comportamento e engajamento dos usuários na ferramenta. Após, os colaboradores foram convidados a responder o questionário individualmente. Esta etapa resultou em grande quantidade de dados e na maior parte das considerações da pesquisa. A última etapa foi a análise dos dados de utilização da ferramenta Intranet no Google Analytics, obtendo mais informações sobre os usos e acessos da ferramenta e permitindo a realização das conclusões deste trabalho. 


\section{USOS E AVALIAÇÕES DO PÚBLICO INTERNO NA INTRANET COPREL}

O primeiro passo empírico deste trabalho foi elaborar o questionário para a realização da pesquisa de comunicação organizacional, destinado a todos os colaboradores. Em um total de 17 questões, inicialmente foram avaliadas questões pessoais e rotinas de acesso à internet de modo geral, com o objetivo de conhecer a que grupo de colaboradores pertencia o respondente. Após, o questionário contemplava assuntos relacionados à rotina de utilização da Intranet na ocorrência de ter possuído contato com a ferramenta.

O colaborador que nunca acessou a ferramenta era convidado a responder questões que tratavam do interesse de conhecer ou não, essa ferramenta de comunicação. Na última parte do questionário, foram inclusas questões que tratavam da comunicação interna de modo geral - nível de informação, canais preferenciais para fazer chegar a informação ao(a) colaborador(a), bem como estímulo para sugestões e avaliações da comunicação interna e da Intranet.

Os questionários foram aplicados em dois momentos. De fevereiro a abril de 2014, foi realizada parte da pesquisa, retomada posteriormente, de julho a setembro, restando poucas pesquisas isoladamente entregues e respondidas em outubro. Obtivemos sucesso na aplicação da pesquisa para $83 \%$ pessoas, com diferente percentual de resposta nas cooperativas e empresas do grupo.

$\mathrm{Na}$ primeira etapa da pesquisa, o questionário foi disponibilizado na Intranet, com permissão de resposta a todos os colaboradores. A chamada para o questionário ficou disponível em destaque, na página inicial, convidando os colaboradores a clicarem no hiperlink ${ }^{8}$ para mais informações e acessarem a página específica da pesquisa, com todo o detalhamento das instruções e questões, explicando também tratar-se de uma pesquisa acadêmica que seria aplicada a todos os colaboradores do grupo.

O resultado esperado desta etapa (mobilizar o maior número de colaboradores para que respondessem a pesquisa) não foi satisfatório. Ao término de duas semanas, obtivemos somente $8 \%$ de participação, com respostas ao questionário. No entanto, todos que responderam a pesquisa pela Intranet fizeram comentários, elogios, críticas e sugestões, ou seja, se mostraram consideravelmente interessados em participar da ferramenta. A apresentação e as análises sobre os dados obtidos por estes questionários serão feitas de forma conjunta com as outras pesquisas.

Os demais colaboradores responderam a pesquisa pelo questionário impresso, após solicitação para tal. Essas pesquisas resultaram em uma grande quantidade de dados, possibilitando analisá-los por empresa, e dentro de cada empresa/cooperativa, sendo organizados em grupos de trabalho, grupos estes definidos a partir das rotinas de trabalho do(s) setor(es). 


\subsection{COPREL COOPERATIVA DE ENERGIA}

A Coprel Energia, além de reunir o maior número de colaboradores, possui maior segmentação de processos/atividades. Do total de colaboradores desta cooperativa, aplicamos com sucesso a pesquisa a 73\% (incluindo as pesquisas via Intranet). Para fins de análise dos questionários, dividimos estes colaboradores em quatro grupos, usando como critério a utilização de internet/computador no trabalho, bem como os turnos de trabalho (horário comercial ou escala/plantão). Os grupos são: administrativo (envolvem os colaboradores que seguem horário comercial e que, quase na totalidade, utilizam computador para o trabalho diário); operação (colaboradores que trabalham no Discopre19, no COD10 e no COS11, setores estes que atuam em regime de escala para cobertura 24 horas), almoxarifado (colaboradores que trabalham no depósito de materiais, e em função disso tem acesso controlado ao computador disponível no setor - seguem horário comercial), e por fim, as equipes de campo (eletricistas e leituristas - que trabalham em regime de escala e somente a campo, utilizando como forma de comunicação no trabalho, apenas o sistema de rádio, e, mais recentemente, tablets com acesso à internet, porém apenas para uso dos sistemas e sem acesso ao navegador para utilizar a Intranet Coprel).

No setor administrativo, a análise das pesquisas revelou um grupo que se sente bem informado (95\%), sendo que o restante apenas não respondeu a questão. Apenas um colaborador pesquisado não possui acesso ao computador e nunca acessou a Intranet. Assim como bem informados, todos se apresentaram críticos e sugestivos. A necessidade de manter conteúdo mais atualizado na Intranet aparece como unanimidade, e é constante nas pesquisas a preocupação deste grupo com os colegas que não possuem acesso a computador. Eles percebem também a necessidade de algumas melhorias de ordem técnica para avançar na localização de conteúdos. Sugerem a criação de campanhas com foco nos gestores para reforçar a importância do acesso, a inclusão de mais assuntos que auxiliem os colaboradores a saberem mais da empresa, e também uma melhor organização dos conteúdos, com melhor padronização da organização - selecionando prioridades e urgências.

No grupo da operação, as pesquisas revelam colaboradores que se sentem menos informados sobre a organização ( $65 \%$ dos pesquisados afirmaram sentirem-se informados). Todos que responderam o questionário possuem acesso a computador e internet, bem como, todos eles já conheciam a ferramenta Intranet. Da mesma forma que o grupo anterior, as respostas aos questionários demonstram que estes colaboradores estão críticos e sugestivos em 
relação à Intranet, sendo também unânimes em afirmar que a ferramenta beneficiou a comunicação interna. Eles alertam para o fato de não poderem participar das atividades do grupo da mesma forma que os demais setores, e que mesmo com a Intranet algumas notícias ainda chegam atrasadas. Neste grupo, solicitam mais informações de uso para o trabalho, e esperam a ferramenta tornar-se mais interativa, a exemplo dos sites de redes sociais na internet. Reconhecem ser necessária a maior participação dos próprios colaboradores para a ferramenta efetivar-se como meio principal de comunicação. Para este grupo, assim como no setor administrativo, a Intranet foi mais uma vez escolhida como o meio mais efetivo de comunicação interna.

No setor de almoxarifado, a etapa prática da pesquisa teve de ser realizada em uma reunião, mesmo assim, o percentual de colaboradores que responderam a pesquisa ficou muito abaixo dos outros setores (apenas 40\%). Já na dificuldade de contatar com os colaboradores, percebe-se que estão mais afastados do centro das informações. Outros $30 \%$ foram contatados, porém não entregaram o questionário. Porém os resultados obtidos através do questionário não revelam maiores problemas de comunicação, comparado aos outros setores: $71 \%$ sentem-se bem informados sobre a organização. Quase a totalidade possui acesso à computador com internet, porém somente em casa. Identificamos neste grupo um colaborador que acessa a Intranet da própria casa - adotou a prática como hábito. Os colaboradores do setor revelam o desejo de ter condições de acessar o computador no trabalho - mas ao mesmo tempo, revelam que também deveria partir deles próprios o interesse e iniciativa de acessar em casa, já que utilizam a internet quase que diariamente. Para este grupo, a Intranet e o informativo interno mensal (formato impresso), seguidos do mural, são as melhores maneiras para mantê-los atualizados sobre as informações da Coprel e demais empresas do grupo.

Neste grupo, a menor amostragem resultou em uma pesquisa sem tanta riqueza de informações como as outras. Soma-se a isso o fato de estes pesquisados situarem-se em uma faixa de escolaridade mais baixa que os demais, o que sugere ser um dos motivos do menor número de sugestões ou críticas. Ainda assim, constatou-se a necessidade de disponibilização do acesso à ferramenta em horário de trabalho e incentivo ao acesso, pois foi relatada a demora na chegada de informações ao setor.

Ainda na Coprel Cooperativa de Energia, analisamos o setor das equipes de campo, os eletricistas. O índice de questionários respondidos foi de 94\%. Estes colaboradores não cumprem horário na cooperativa e sim, nos municípios onde residem. As pesquisas foram respondidas em reuniões de equipe. Estes colaboradores trabalham a campo, e não necessitam 
de computador para o trabalho. O percentual de colaboradores deste grupo que possui acesso à computador é de $86 \%$. Neste setor, os funcionários demonstram estar mais alheios aos acontecimentos da empresa: foram $52 \%$ dos entrevistados que disseram sentirem-se bem informados. Diferente dos demais grupos, segundo eles as reuniões funcionam como melhor alternativa para mantê-los bem informados pela empresa, seguidos de perto pelo informativo interno (versão impressa) e depois pela Intranet. O número de colaboradores neste setor que já acessou alguma vez a Intranet é de 55\%.

O estudo dos questionários respondidos por este grupo revelou a maior quantidade de colaboradores insatisfeitos com a comunicação interna. Muitos reclamaram da demora no recebimento de informações. Ainda assim, recebemos retornos positivos quanto à utilização da Intranet - é importante considerar que neste grupo o acesso à ferramenta, além de ter sido feito por apenas pouco mais da metade dos colaboradores, ocorre somente de forma esporádica. Nota-se que existe engajamento também neste setor, e que muitos estão preocupados em estar bem informados e conhecer melhor a empresa para melhorar o atendimento aos cooperantes, ou seja, ao público externo.

\subsection{COPREL COOPERATIVA DE GERAÇÃO DE ENERGIA E DESENVOLVIMENTO}

A Coprel Geração reúne menor número de colaboradores, comparada à Coprel Energia, no entanto os setores que compõem as duas cooperativas se assemelham, nos critérios de delimitação expostos neste trabalho. A título de organização das pesquisas, temos os seguintes grupos: administrativo, usinas e fábrica de postes. No setor administrativo, ou seja, no escritório principal, são três colaboradores, cujo padrão de resposta se assemelha ao setor administrativo da Coprel Energia. São funcionários com acesso a computador e internet, que acessam a Intranet diariamente, sentem-se bem informados como colaboradores e sugerem melhorias, como as de ordem técnica para induzir que as pessoas obrigatoriamente acessem os conteúdos.

Os colaboradores do grupo aqui chamado de "usinas" se assemelham às equipes de campo da Coprel Energia. São funcionários que trabalham a campo, muitos inclusive moram em diferentes municípios. Conseguimos aplicar a pesquisa a uma amostragem de 46\%. Metade do grupo não se sente bem informado sobre a empresa, assim como a metade ainda não havia acessado a Intranet. Contudo, quase todos declaram que a Intranet é a melhor forma de comunicação interna. Percebemos neste grupo a preocupação com as informações extraoficiais 
e boatos que circulam na empresa, que segundo um dos pesquisados, se espalham mais rapidamente que as próprias informações de interesse dos funcionários. Nos questionários também foi destacado que falta comprometimento por parte dos colaboradores de acessarem a ferramenta.

No terceiro e último grupo da Coprel Geração, o da Fábrica de Postes, as pesquisas foram aplicadas para $77 \%$ do grupo. Este setor é comparável ao "almoxarifado" da Coprel Energia, pois os colaboradores, apesar de trabalharem junto à sede da cooperativa e em horário comercial, não possuem acesso a computador no trabalho. Este grupo se destaca pela quantidade de colaboradores que não possuem acesso a computador: quase a metade do grupo pesquisado. Apenas $9 \%$ haviam acessado a Intranet até o momento da pesquisa. Conforme os resultados do questionário, o grupo se mantém mais informado pelo informativo interno. Um terço dos pesquisados se diz bem informado, um terço não se considera bem informado e o restante não respondeu a este questionamento. Neste grupo, foram respondidas basicamente as perguntas fechadas do questionário, sendo que as demais foram deixadas em branco, o que nos impossibilita de trazer para análise os comentários dos colaboradores. Fazem-se necessários esforços diferenciados para integrar essa parte da equipe, em razão das menores taxas de escolaridade e de acesso à informática.

\subsection{TRIWAY}

Por ser a empresa do grupo que reúne o menor número de colaboradores, a expectativa era de obter o melhor percentual de amostragem, porém foram encontradas dificuldades na aplicação dos questionários, principalmente, na não devolução dos formulários entregues assim, conseguimos entrevistar apenas 59\% do grupo. Para análise dos dados, organizamos o Triway em dois departamentos: comercial e técnico. Pelo fato de trabalharem em uma operadora de telecomunicações, todos os colaboradores possuem o domínio necessário de computador para acessar a Intranet sem dificuldades. A maior parte dos funcionários de ambos os departamentos trabalham a campo, passando parte do dia sem acesso ao computador, contudo, possuem condições de acessar a ferramenta por realizarem algumas funções através de smartphones e tablets. Todos os colaboradores pesquisados já haviam acessado a Intranet, e $70 \%$ se sentem bem informados como colaboradores. Neste grupo, a ferramenta preferida para obter informações é o e-mail, seguida de perto pela Intranet. O grande diferencial nas pesquisas aplicadas a este grupo foram os comentários sobre a Intranet e a comunicação interna: a maioria 
reconhece a Intranet como uma excelente ferramenta de comunicação, e ao mesmo tempo refletem no sentido de que a utilizam pouco. Este grupo pede mais interatividade na ferramenta e melhores níveis de personalização, agregando mais funções. Por utilizarem muito o e-mail, defendem que o envio de e-mails sobre as informações mais importantes deve servir como gerador de tráfego para a Intranet.

\subsection{AMISA}

Para a apresentação dos dados obtidos na aplicação das pesquisas na Amisa, onde a amostragem de pesquisas entregues respondidas somou $94 \%$ dos colaboradores ( $9 \%$ do total de colaboradores respondeu o questionário pela Intranet), consideramos quatro unidades/departamentos: Amisa Ibirubá (envolve os colaboradores que trabalham na parte administrativa, vendas e serviços da Amisa em Ibirubá; Amisa Panambi (reúne os funcionários das mesmas funções que na Amisa Ibirubá, porém no município de Panambi, somando ainda os colaboradores que trabalham na loja de Palmeira das Missões); Posto Amisa de Ibirubá, e Posto Amisa de Quinze de Novembro.

$\mathrm{Na}$ Amisa Ibirubá, grande parte dos colaboradores possui acesso a computador no trabalho, e a quase todos utilizam computador em casa também. O percentual de colaboradores que acessou a intranet é de $81 \%$, e a ferramenta é, segundo as respostas dos questionários, a melhor forma de se manter informado sobre os assuntos da empresa e do grupo, seguido do email. Sobre o índice de colaboradores que sentem-se bem informados, chegou-se ao percentual de $71 \%$, sendo que o restante se dividem entre colaboradores que não se consideram bem informados sobre os assuntos da empresa, e pessoas que não responderam a questão. Em relação aos comentários feitos sobre a efetividade da Intranet e da comunicação interna, percebe-se uma disparidade muito grande. Enquanto vários colaboradores declaram que a comunicação interna está ótima, houve também comentários de insatisfação, de colaboradores que sentem-se excluídos de algumas informações, ou que percebem muita diferença entre as empresas (Coprel, Triway) e a própria Amisa. Alguns citaram a necessidade de computadores para acesso no trabalho, e outros consideram que o interesse deve partir do colaborador e que muitos não demonstram interesse em estar bem informados. Foram feitas ainda, sugestões como aumentar o número de publicações na intranet e inserir informações a respeito do mercado automotivo.

Na Amisa Panambi, todos os colaboradores possuem acesso à computador, sendo que $81 \%$ utiliza o computador no trabalho, e $73 \%$ já acessaram a intranet. O padrão de respostas obtidas pelos questionários é semelhante ao obtido em Ibirubá: 70\% dos colaboradores se 
consideram bem informados, e dentre os comentários sobre a Intranet e a comunicação interna, percebeu-se a mesma disparidade encontrada em Ibirubá: muitos colaboradores elogiando a comunicação e a ferramenta, enquanto outros, ao contrário, se mostram insatisfeitos. Deste grupo, o maior motivo de insatisfação se difere de Ibirubá: a demora na chegada das informações é tida como a "vilã" da comunicação interna. Outra característica peculiar neste grupo é o uso do e-mail, que não foi citado como um dos canais mais importantes de informação sobre a empresa: a Intranet e o Informativo Copreliano são os meios de comunicação interna mais utilizados pelos colaboradores da Amisa Panambi.

Os postos de Ibirubá e Quinze de Novembro apresentaram padrões de respostas semelhantes entre si. Os questionários apresentaram poucas sugestões, reclamações ou comentários (o que parece ser reflexo do menor nível de escolaridade média do grupo), e dentre as poucas considerações feitas pelos colaboradores, a maior parte delas diz que está satisfeita com a comunicação, o que se revela pelo índice de colaboradores que dizem sentir-se bem informados sobre a empresa (75\% em Ibirubá e 71\% em Quinze de Novembro), semelhantes também com os demais setores da Amisa. Nos dois postos de combustíveis, a maior parte dos colaboradores ainda não havia acessado a intranet. $\mathrm{O}$ acesso ao computador no trabalho é limitado, porém quase a totalidade dos colaboradores utiliza computador em casa. Houve considerações a respeito de uma melhor divulgação da Intranet entres os colaboradores, para conhecimento da ferramenta e para estimular o acesso.

\subsection{CONSIDERAÇÕES A PARTIR DOS DADOS DE ACESSO}

Através da ferramenta Google Analytics, obtivemos mais alguns dados de acesso e comportamento dos usuários na Intranet. O período avaliado foi de 10 de setembro a 10 de outubro de 2014 - não pudemos analisar os acessos no mesmo período da pesquisa com os colaboradores por questões de ordem técnica, necessárias para configurar as permissões de coleta de dados da Intranet pela ferramenta do Google, o que só feito a partir de 10 de setembro. O uso destes dados fornece um panorama geral de uso, porém não permite o acesso aos mesmos detalhes de um site comum, em razão das configurações técnicas da ferramenta (muitas interações do usuário são feitas sem que isto configure o acesso a uma nova página). $\mathrm{O}$ que percebemos neste período foi um número bruto de visualizações de página alto (38.503), ultrapassando o acesso do próprio site da Coprel (37.127) e ficando próximo ao número de acessos do site da Amisa (42.783). O tempo médio de sessão12 no site também é alto $(6,04$ min), o que demonstra que os usuários se utilizam dos conteúdos e informações disponibilizadas 
na ferramenta. Porém, ficou muito evidente que existe pouco tráfego nas páginas "acessórios" do site. A concentração de acesso é na página inicial (48,53\%): que é a página que os colaboradores acessam ao entrar na ferramenta e que reúne a maior parte das informações; seguido da página de sistemas (16,08\%): local de acesso à todos os sistemas do grupo. Em terceiro lugar no ranking de acesso, retorna a página inicial $(14,80 \%)$, porém o acesso a esta página significa que o colaborador estava em outro local da intranet e, internamente, escolheu voltar para a página inicial. A quarta página mais acessada é a da Ascoprel13, com 5,11\% dos acessos; depois, está a página de "informações importantes" com 1,06\% dos acessos, seguida da página que apresenta ingressos para eventos (disponíveis aos colaboradores), com 1,02\%. As demais páginas não somaram $1 \%$ de acesso. É importante considerar que, na página inicial, são feitas diversas interações que não são computadas como mudança de tela (acesso às notícias, dicas, ramais). Contudo, fica evidente que não há um aproveitamento da ferramenta no sentido de ampliar a navegação dos usuários em mais informações sobre a empresa, como no acesso aos documentos (esta página consta como a $13^{\mathrm{a}}$ mais acessada, com 181 visualizações/interações: 0,47\%).

Quanto aos dias/horários de maior acesso, se concentra de segunda a sexta-feira, com grande queda no sábado e menor acesso ainda no domingo. Fica evidente a existência de três "horários nobres" na intranet, são eles: o começo da manhã, o começo da tarde e o final da tarde - padrões que se repetem também no final de semana.

\section{CONSIDERAÇÕES FINAIS}

A produção deste trabalho foi um processo muito revelador e produtivo, afinal, aplicar ciência à vivência profissional não é algo muito comum. Um trabalho como este reforça a importância da pesquisa científica e das reflexões sobre o fazer.

Pode-se concluir que a Intranet é uma ferramenta que agregou valor à comunicação interna do grupo Coprel. Seu uso se popularizou entre os colaboradores que estão no dia-a-dia em frente ao computador, por reunir os acessos necessários aos sistemas de trabalho, informações do dia-a-dia e complementos, como notícias relacionadas ao público interno, dicas, listagem de aniversariantes, entre outros. No entanto, há uma grande lacuna na falta de interatividade do sistema e na falha em reunir documentos e informações de uso comum que incentivem o colaborador a ter na Intranet um agregador de conhecimento compartilhado das empresas. 
Quanto à comunicação interna, o grupo desenvolve diferentes estratégias para levar informação aos seus colaboradores - órgão informativo interno impresso mensalmente, reuniões, uso do mural, e-mail, entre outros, porém, foi interessante observar que a maioria dos colaboradores - até mesmo os que não acessam a intranet com frequência, consideram a ferramenta o melhor meio de se manter informado sobre a empresa. Desta forma, se justifica o investimento de recursos e pessoal para efetivar as sugestões de ações que serão expostas a seguir, e outras possíveis iniciativas que devem se somar a estas, a partir da continuidade prática deste trabalho com o término da pesquisa.

Conforme apontado na análise do Google Analytics, é necessária uma reorganização das informações da Intranet, que direcione a navegação para mais áreas de interesse, mudando o status da ferramenta de atual depositária de informações e acesso de sistemas a um portal de comunicação interno.

Este trabalho revela ser necessária a reelaboração de estratégias de ordem operacional na ferramenta. Em primeiro lugar, o layout e a ordenação dos conteúdos devem ser repensados. O ideal será um trabalho conjunto entre um profissional da comunicação (para redesenhar a estrutura da ferramenta utilizando os padrões de usabilidade na Internet,) com o auxílio de um webdesigner14 (para criação visual e gráfica). A pesquisa feita nos permite sugerir que se devem realocar alguns dos itens da página inicial para outros submenus, incentivando a navegação em mais páginas da ferramenta e possibilitando a mensuração destes acessos no Google Analytics. Os assuntos, conteúdos, informações e recados que são inseridos na Intranet deverão ser ordenados por área de interesse e/ou ordem de importância, e seguir padrões de divulgação destes itens. Os departamentos e setores devem ser organizados de forma mais usual, facilitando o acesso. Após essa reordenação, é o momento de um novo treinamento dos gestores, para que eles tenham domínio da inserção de conteúdos na Intranet. Outra ação necessária é a designação de um responsável por alimentar a ferramenta, em cada setor, inserindo os documentos e informações mais importantes de cada departamento.

Para tornar a ferramenta mais interativa, sugere-se a criação de fóruns de discussão e enquetes, e a disseminação de conhecimento institucional através da organização de processos, por exemplo: cada setor pode ser desafiado a documentar um processo de trabalho semanal ou quinzenalmente, e inseri-lo na Intranet, ou ainda, documentar o planejamento e lista de tarefas de cada colaborador, para o bom andamento das atividades. Este processo deve trazer todos os passos de execução de determinada tarefa. Ao ser colocado na Intranet, de certa forma perpetuase o conhecimento produzido na organização - conteúdo que muitas vezes deixa a empresa quando um colaborador sai do emprego. 
Como forma de incentivar as pessoas que não costumam acessar a Intranet, se sugere também essa documentação de processos/rotinas do setor, para posterior postagem na Intranet (de forma orientada). Outra ação é integrar conteúdos e até mesmo brincadeiras do Informativo Copreliano com a Intranet, incentivando o acesso pelos colaboradores que não possuem o hábito de utilizar a ferramenta. Percebeu-se na realização da pesquisa que os colaboradores que não utilizam a Intranet com frequência, esqueciam o login e a senha e acabavam por não solicitar novo acesso. Neste sentido, pode ser feita uma ação pontual de sorteio ou promoção, disponibilizar o resultado ao(s) colaborador(es) premiado(s) somente na Intranet - todos terão que acessar a Intranet para saber se foram contemplados.

Também será necessário um treinamento para orientar os colaboradores que não utilizam computador para aprenderem a acessar a Intranet. Por parte da empresa, é imprescindível a disponibilização de computadores em todos os setores e a conscientização de todos os gestores para delimitarem um horário de acesso diário ou periódico para cada colaborador. É fundamental considerar que um dos negócios do grupo Coprel é a venda de tecnologia (Internet e Telefonia), então a força do grupo deve se efetivar inicialmente "dentro de casa", com a disponibilização e incentivo de acesso pelos próprios colaboradores. Ainda com relação à unidade existente entre a proposta da Intranet e a empresa Triway, propõe-se colocar em discussão a possibilidade de a empresa oportunizar aos colaboradores acesso à cursos básicos de informática, na forma de auxílio-educação, bem como estudar maneiras de auxiliar esse colaborador a adquirir um computador.

Ainda em termos de disponibilização de tecnologia, será interessante colocar em avaliação a produção de um aplicativo para celular com as mesmas funções que a Intranet possui em um navegador utilizado nos computadores.

Por fim, com o objetivo de melhorar a comunicação interna - já que a pesquisa apontou alguns problemas neste sentido, se faz necessária a continuidade e reforço das ações já desenvolvidas nos demais meios de comunicação interna, que tem aceitação e são importantes aos colaboradores, como: o informativo interno, as reuniões, os e-mails, o uso de mensagens de celular (sugerido pelos colaboradores na pesquisa). Sugere-se o envio periódico de e-mails, aos colaboradores trazendo alguns destaques da Intranet, dicas e informações, mas sem o conteúdo integral - este deverá ser visualizado na Intranet.

Como a própria aplicação da pesquisa revelou, para conseguir chegar até o colaborador, é necessária uma rotina de contato, acesso e compartilhamento de informações, o que deve ocorrer fora do posto de trabalho, principalmente nos setores em que o funcionário 
não utiliza o computador. $\mathrm{O}$ incentivo para que os funcionários acessem a intranet de 5 a 10 minutos por dia não vai fazê-los "perder tempo", e sim, acumular conhecimento que agregará valor nas 24 horas do dia, onde quer que o colaborador esteja. Já para os funcionários que já utilizam a intranet como ferramenta de trabalho, cabe aos responsáveis por administrá-la a responsabilidade de mantê-la viva, alimentando-a com conteúdo de relevância (tanto de uso profissional como pessoal), e principalmente, promover a interatividade da ferramenta: característica que se faz cada vez mais fundamental nos sistemas de comunicação existentes hoje.

\section{NOTAS}

1 O termo "Intranet" refere-se a uma rede interna de computadores conectados via web, em alguma instituição ou empresa. Seu uso e conteúdo é restrito aos funcionários de determinada instituição/empresa. É um canal de comunicação que visa facilitar o acesso à informações, documentos e registros importantes de uso institucional, bem como compartilhar informações e incentivar a interação entre colaboradores.

2 Neste trabalho, os termos 'colaboradores' 'funcionários', 'empregados', são utilizados como sinônimos, e significam todo o trabalhador que possui vínculo empregatício com uma das empresas pesquisadas, firmado através de contrato de trabalho.

3 Nesta citação o sentido da palavra "cliente interno" é o mesmo de "colaborador".

4 "Cooperantes" é o termo usado pela cooperativa para designar seus associados ou cooperados, o que equivale aos clientes de uma empresa.

5 Trecho extraído do e-book "Comunicação corporativa: desafios, planos e soluções tecnológicas", da empresa Social Base. Disponível em: http://blog.socialbase.com.br/files/2013/02/eBookcomunicacao-corporativa-desafios-planos-e-solucoes-tecnologicas.pdf. Acesso em: 10/11/2013.

6 Dados de acesso fornecidos exclusiva e secretamente a cada colaborador, de forma que somente o indivíduo que possui esses dados pode acessar a ferramenta.

7 Ferramenta on-line que permite a análise digital de websites na internet, bastando para isso uma integração com a administração de determinado site. Possibilita o acompanhamento geral do tráfego no site, incluindo detalhamento do acesso, saídas, páginas mais acessadas, entre outros. Fonte: adaptado de http://support.google.com/analytics. Acesso em 10 de outubro de 2014.

8 O termo se refere a um determinado campo em uma página web, que ao ser clicado (acionado), remete a uma nova página.

9 "Discoprel" é o nome utilizado para designa o callcenter da cooperativa, que recebe as ligações dos cooperantes.

10 "COD" é a sigla utilizada para "Centro de Operação da Distribuição", setor em que trabalham os colaboradores que gerenciam ocorrências entrantes via Discoprel e designam as equipes de eletricistas a campo para os trabalhos. 
11 "COS" é a abreviatura de "Centro de Operação do Sistema", que gerencia usinas e realiza as operações automáticas relacionadas ao sistema elétrico.

12 Sessão é o período de tempo em que um utilizador interage ativamente com o website, neste caso, a Intranet.

${ }_{13}$ Associação de Funcionários do grupo

${ }^{14}$ Profissional especializado na elaboração do projeto estético de websites na internet.

\section{REFERÊNCIAS}

DUARTE, Jorge; BARROS, Antonio (orgs). Métodos e técnicas de pesquisa em comunicação. $2^{\mathrm{a}}$ ed. $4^{\mathrm{a}}$ reimpr. São Paulo: Atlas, 2010.

CINEGAGLIA, Maria Natalina. Bases para refleitr sobre o endomarketing e a comunicação interna. In: FRANÇA, Ana Shirley (org.). Comunicação Empresarial. Editora Atlas, 2013.

CORRÊA, Elisabeth Saad. Comunicação digital: uma questão de estratégia e de relacionamento com públicos. Organicom, 2005. Disponível em: http://www. academia.edu/ 8194934/KEY_WORDS_DIGITAL_COMMUNICATION_STRATEGIC_COMMUNICATI ON_ORGANIZ̄ATIONĀL_COMMŪNICATION_INTEGRATED_Resumen. Acesso em: 06 de junho de 2014.

MOTTA, Ricardo. Análise do atual ambiente competitivo e as estratégias que devem ser adotadas pelas empresas para obterem sucesso. In: EAESP / FGV (org.) Revista de Administração de Empresas. São Paulo, 1995. Disponível em: http://www.scielo.br/pdf/rae/ v35n2/a03v35n2.pdf. Acesso em 08 de junho de 2014.

RECUERO, Raquel. Redes sociais na internet. Porto Alegre: Sulina, 2009.

SCROFERNEKER, Cleusa Maria Andrade. Afinal, o que é Comunicação Interna? In: DORNELLES, Souvenir Maria Graczyk (org.) Relações Públicas: quem sabe, faz e explica. Porto Alegre: EDIPUCRS, 2007. 